\title{
Overview of Sub-synchronous Oscillation in Wind Power System
}

\author{
Han Chen, Chunlin Guo, Jianting Xu, Pengxin Hou \\ State Key Laboratory for Alternate Electrical Power System with Renewable Energy Sources, \\ North China Electric Power University, Beijing, China \\ Email: chensheshijia@ncepu.edu.cn
}

Received April, 2013

\begin{abstract}
Nowadays with the improvement in the degree of emphasis on new energy, the wind power system has developed more and more rapidly over the world. Usually the wind plants are located in the remote areas which are far from the load centers. Generally series compensated AC transmission and high voltage DC transmission are made use of to improve the transmission capacity as two main effective ways which can solve the problem of large scale wind power transmission. The paper describes the three kinds of impact varieties and impact mechanisms in the sub-synchronous oscillation phenomena of wind power system based on doubly fed induction generator (DFIG) wind generators. At last, we point out the important problem that should be stressed in the wind power system.
\end{abstract}

Keywords: Sub-synchronous Oscillation (SSO); Sub-synchronous Resonance(SSR); Sub-Synchronous Torsional Interactions (SSTI); Sub-Synchronous Control Interactions (SSCI); Wind Turbines; Doubly-fed Induction Generator

\section{Introduction}

Sub-synchronous oscillation phenomenon in the thermal power system is in an abnormal state that the steam turbine unit is being under special operation state after disturbance, on the running condition, electrical system and steam turbine generator set are having significant energy exchange at one or more the synchronous frequency. The year 1970 and 1971, there is a severe large-scale turbogenerator rotor shaft damage caused by transmission series compensation capacitor[1]. After this accident, people in academic and industry began to study sub-synchronous oscillation problem hotly, and achieved remarkable results in mechanism analysis method and the restraining method.

Nowadays the wind power system has developed more and more rapidly which has become the most important part of the energy strategic planning.

However as the wind power plant is far from the load center, series compensated AC transmission and high voltage DC transmission are used widely to settle the large scale wind power transmission problem. Series compensation may induce sub-synchronous oscillation problem of wind turbine, affect the safe and stable operation of wind farms as well as the transmission system $[2,3]$. Sub-synchronous oscillation in a wind farm in the form of three kinds of mechanism is discussed based on the current mainstream models doubly-fed induction ge- nerator (DFIG), and we pointed out that the current problems faced now.

\section{The Simple Analysis of Sub-synchronous Oscillation Problem in Wind Power System}

\subsection{Introduction of Doubly-fed induction Generator (DFIG)}

The working principle of doubly-fed induction generator is that the frequency converter generates a low-speed rotating magnetic field in the rotor winding. The speed of rotating magnetic field $\mathrm{n} 1$ is added up with the rotor mechanical speed $\mathrm{n} 2$ driven by wind and it forms a rotating magnetic field in the rotor winding of which the speed is $\mathrm{n}$, that means: $\mathrm{n} 1+\mathrm{n} 2=\mathrm{n}$. When the wind speed changes, changes along, the CPU calculate the inverter output frequency of the rotor current according to expression . By changing the frequency $\mathrm{n} 1$ of the rotor currents to adjust the rotational speed of the rotating magnetic field, it is possible to compensate for the changes in speed of the generator rotor, thereby maintaining the constant output frequency of the grid [4].

As the double-fed asynchronous generator only flow through the slip power inverter, inverter capacity is relatively small, usually about $10 \%$ to $30 \%$ of the rated generator power. The loss and the investment are relatively 
low, the technology is mature, so it's the most mainstream fan [3]

The current amplitude, phase, frequency of doubly fed induction motor rotor excitation can be adjusted; the active power, reactive power can be adjusted too; excellent network characteristics; therefore, doubly-fed induction motors currently are the most promising wind turbine.

Due to the different mechanism of sub-synchronous oscillation, there are different kinds of math model, analysis method and solutions. The structural characteristics of the wind turbine have decided that the SSO problem caused by series compensated AC transmission and high voltage DC transmission is not all the same. In addition to possible sub-synchronous resonance (SSR) and sub-synchronous torsional interactions (SSTI), wind turbines converter internal control may also cause subsynchronous oscillation problem (SSCI). [4]

\subsection{The Sub-synchronous Resonance in Wind Power System}

According to IEEE working group, the definition of subsynchronous resonance (SSR) refers to electro-mechanical oscillatory behavior caused by the coupling between Turbine and transmission system(Figure 1) with the series capacitor compensation. Because the rendered weak damping of the oscillations, un-damping, even negative damping characteristics, the trend of the amplitude of this oscillation is gradually increasing.

Electrical oscillation frequency as shown in type (1),

$$
f_{e r}=f_{0} \sqrt{\frac{X_{C}}{X^{\prime \prime}+X_{E}+X_{T}}}
$$

where, $f_{0}$ is the synchronous frequency, the impedance $X$ is based on the electrical frequency corresponding to average rotor speed $f_{0}$. Under ideal conditions, $f_{0}$ is equal to synchronous frequency.

When there is the current whose frequency is the resonant frequency in the stator winding, the rotor windings will produce the rotor current of which the frequency is $f_{r}$. To three-phase armature current, it will produce the rotating magnetic field of the positive and negative sequence in the synchronous generator. In the joint action of each phase current time distribution and spatial distribution of each armature winding, the frequency of electrical angular velocity of the magnetic field rotation is $2 \pi f_{e r}$. The rotor frequency of the current caused by rotating magnetic field is determined by the relative speed of the rotating magnetic field and the rotor. Thus, the positive sequence component of the stator current will produce rotor current component $\left(f_{r}=f_{0}-f_{e r}\right)$. If the generator shafting torsional vibration frequency in natural is at the frequency of $f_{r}$, that is to say, the system electrical resonant frequency and gen- erator shafting natural torsional vibration frequency are complementary. Then the energy exchange happened. Between generator and series compensation system through continuous weakly damped oscillation and transient effect. Oscillation caused by the mutual encouragement may maintain or may lead to instability.

Double-fed induction wind power unit shaft system has the characteristics of low natural frequency of torsional vibration. This means that if sub-synchronous resonance is to occur, if the system should have a high electrical resonant frequency, meaning a high degree of Line Series Compensation. For wind turbine, it's more difficult to have the SSR problem compared to the thermal power units. Paper [5] Unified Power Flow Controller (UPFC) is used to enhance the wind farm system stability, at the same time, it can increase sub-synchronous damping of system to suppress sub-synchronous resonance of wind turbines. It can produce corresponding sub-synchronous damping torque by adding additional control and improving UPFC control strategy in the pitch angle control to achieve the purpose of sub-synchronous resonance suppression. Paper [6] established the impedance model of the wind turbine and the electrical system and analyzed the SSR stability between the doubly-fed induction wind turbine and series compensation network using Nyquist and Bode diagram. Finally it concluded that low wind speed are more damaging than high wind speed for SSR, and RSC current controller is not very good to reduce SSR.

The document $[7,8]$ designed SSR damping controller for the doubly fed induction wind turbine and verified the validity through a numerical example simulation. These data models are most used in single - infinity system equivalent model and the series compensation degree is generally higher than real wind power system, SSR causes cannot be explained using the time domain model from the aspects of mechanism.

\subsection{Sub-synchronous Torsional Interactions (SSTI)}

HVDC and SVC, PSS device -- quick power regulation devices are likely to stimulate torsional vibration. The oscillation is called "devices caused sub-synchronous oscillation (device dependent sub-synchronous oscillation)". With further study of the SSO problems, researchers this time called the synchronous oscillation

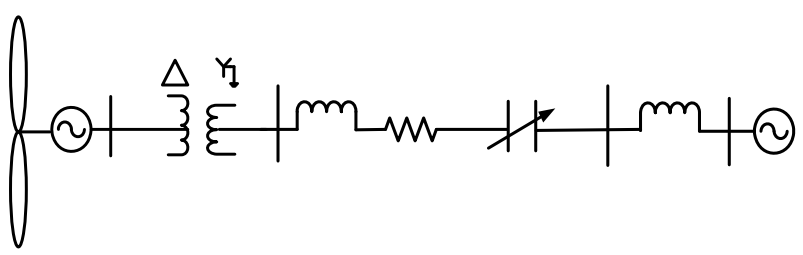

Figure 1. Simple wind power system model. 
problem as sub-synchronous torsional vibration interaction (SSTI), defined as the interaction at sub-synchronous frequency occurring between the generator and the shaft power control equipment. Here it mainly refers to the interaction between the wind generator controller and unit shaft system, this phenomenon occurs in complementary electrical frequency with shafting mode state frequency, if the system having negative damping. In a test of the Square Butte HVDC converter station in America, there is the $30.5 \mathrm{~Hz}$ sub-synchronous current component happening in the DC transmission system, followed by the induced serious shaft torsional vibration near turbo-generator. This is the first report about the HVDC induced generator torsional vibration and it has attracted close attention of scholars all over the world. The analysis after the accident showed that the occurrence of sub-synchronous oscillation is related to the way of the dynamic characteristics of the HVDC transmission system regulation [1].

The paper [9] described the SSTI specific behavior by PSCAD / EMTDC time domain simulation of the induction fan speed. It conducted the disturbance analysis of different rotational component at zhe modulation frequency and analysed the reason of sub-synchronous oscillation in the wind power system with HVDC transmission lines. The paper [10] also summarized the sub-synchronous oscillation reason of different types of wind turbines, analyzed the double-fed induction motor, and found that SSTI occurred usually in a lower degree of series compensation system through simulation. The SSTI problem is very complicated and we need consider the electromechanical transient process and electromagnetic transient process of the network and the system controller at the sub-synchronous frequency [11]. The wind power system started up later and most of the studies are about the HVDC in traditional power system. And the study of SSTI in wind power system is less and less. This phenomenon may be solved by adding a special damping controller [12,13].

\subsection{Sub-synchronous Oscillation Problem Caused by Wind Turbines Converter Internal (SSCI)}

This SSCI problem is mainly the interaction of the wind turbine controller and series compensation system, which is the form of wind turbine different from the thermal power units. Actually, SSCI is not only limited to the wind turbine and other FACTS Controller (SVC, STATCOM, etc.) with series compensation system interactions are likely to induce SSCI [10]. SSCI phenomenon leads to negative damping of the system with the fast direct current control of the wind turbine. SSCI is completely unrelated with the wind turbine shafting unlike SSR and SSTI. SSCI is only the interaction between the generator control system with fixed series compensation, the oscillation frequency is determined by the generator control system and transmission line parameters. In addition, compared with the SSTI and SSR, due to SSCI having no participation function with the mechanical system, the oscillation damping effect of the system is smaller, so oscillation caused by SSCI spreads faster.

In September 2009, a wind farm in Texas of the United States a SSCI accident happened, which caused a large number of wind turbines fault and internal lever circuit damage, then record waveforms are shown in Figure 2 below [11].

It is currently released SSCI accident for the first time. Accident happened because that the line from wind farm had a ground fault and broken then, the system connection mode changed and at last formed the radial power connection mode at which wind farm and the system fixed by a single line of series compensation (75\%). After the accident, a sustained increase of oscillation phenomenon happened between the wind turbine control system and the fixed series compensation, and there is serious distortion of voltage and current. Approximately 0.25 s later, the current increased to about $300 \%$ of the wind turbine rating, the voltage increased to about $150 \%$, which had great damage to the wind turbine. After 3s, fixed series compensation protection device made the fixed series compensation bypassed, the line oscillation was gradually suppressed, SSCI disappeared. This phenomenon has attracted extensive attention of scholars at home and abroad, and they have been studying the mechanism and its suppression measures.

Sub-synchronous oscillation caused by the wind turbine controller is caused by the resonant current of the electrical resonant circuit. To the wind power system using series compensation, harmonic current induced the corresponding sub-synchronous frequency current in the rotor of the generator [12-14].

The current will cause the rotor current waveform distortion and phase offset, the converter controller will adjust the inverter output voltage after the change, then changes the actual current in the rotor and so forms a closed loop system. If the output voltage helps increase

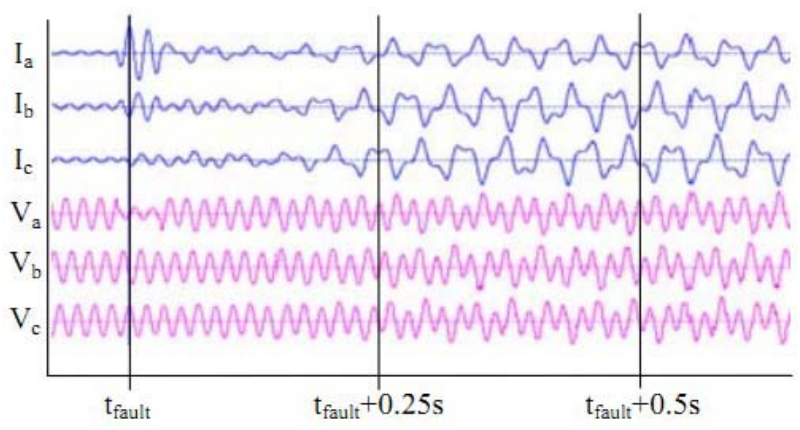

Figure 2. Texas wind farm SSCI wave record chart. 
the rotor current, the harmonic current oscillation will be unstable, resulting in the instability of the whole system oscillation.

The literature [15] outlined the SSCI problem about the doubly-fed induction generator, and that achieved great SSCI suppression effect by designing the damping controller. But the damping controller is designed for specific control effect and does not have the universal applicability .Paper [16] overviewed the reason of SSCI phenomenon in wind power system through comprehensive simulation based on ERCOT models and specific models and told us that the Type 4 wind turbine don't have the SSCI problem.

\section{Conclusions}

Along with the rapid development of wind power, it's more possible to send the power of great capacity. However, as two ways to send the wind power, series capacitor compensation and HVDC may bring sub-synchronous oscillation problems. At present, there are few studies on sub-synchronous problem caused by wind turbine. This paper discusses three kind of action mechanism of subsynchronous oscillations in the wind farm based on the doubly fed induction generator (DFIG) and introduces the foreign research directions and conclusions. For the synchronous oscillation problem triggered by wind turbine, the grid connection ways of the wind farm is different from that in traditional thermal power generation due to the structure of the wind power system. Regardless of the mechanism or the modeling, or suppression measures, there are many questions to be solved.

\section{Acknowledgements}

The paper is supported by the Key Project of the National Research Program of China(2011BAA01B02) and the National High Technology R\&D Program of China(863 Program)(2011AA05A109).

\section{REFERENCES}

[1] S. J. Cheng, Y. J. Cao and Q. Y. Jiang, "Theories and Methods of Sub-synchronous Oscillation with Power System,” Beijing: Science Press, 2009.

[2] T. S. Bi, Y. L. Kong and S. W. Xiao, "Review of Sub-synchronous Oscillation with Large-scale Wind Power Transmission,” Journal of Electric Power Science and Technology, Vol. 27, No. 1, 2012, pp. 10-15.

[3] National Development and Reform Commission, "Renewable Energy and Long-term Development Planning," [EB/OL].http: //www.cwea.org.cn/, 2007-08-31.

[4] X. L. Liu, “Analysis of Major Types of Wind Turbines and the Application of Technology," Electrical Manufacturing, 2009, pp. 18-20.

[5] G. D. Irwin, "Sub-synchronous Interaction with Wind Turbines,” Technical Conference-CREZ System Design and Operation, Taylor, Texas, USA, 2010.

[6] W. Gu, X. Y. Li, Y. H. Wang, Z. L. Mu and W. Wei, "Mitigation Effects of UPFC on Sub-synchronous Oscillation in a Wind Farm," Automation of Electric Power Systems, Vol. 34, No. 8, 2010, pp. 101-105.

[7] Z. X. Miao, “Impedance-Model-Based SSR Analysis for Type 3 Wind Generator and Series-Compensated Network," IEEE Transactions on Energy Conversion, 2012, pp. 984-991. doi:10.1109/TEC.2012.2211019

[8] R. K. Varma, "Soubhik Auddy, Ysni Semsedini Mitigation of Subsynchronous Resonance in a Series-Compensated Wind Farm Using FACTS Controllers," IEEE Transactions on Power Delivery, 2008, pp. 1645-1654. doi:10.1109/TPWRD.2008.917699

[9] G. D. Irwin, A. Isaacs and D. Woodford, "Simulation Requirements for Analysis and Mitigation of SSCI Phenomena in Wind Farms," Transmission and Distribution Conference and Exposition, 2012 IEEE PES, 2012, pp. 1-4.

[10] R. M. Mathur and R. K. Varma, "Thyristor-based FACTS Controllers for Electrical Transmission Systems,” IEEE Wiley-Interscience, 2002.

[11] G. D. Irwin, "Sub-synchronous Interactions with Wind Turbines,” Technical Conference-CREZ System Design and Operation. January 26, 2010, Taylor, Texas, USA.

[12] C. X. Zhu, L. L. Fan and M. Q. Hu, "Control and Analysis of DFIG-based Wind Turbines in a Series Compensated Network for SSR Damping,” Power and Energy Society General Meeting,2010IEEE Digital object Identifier;10.1109/PES.2010.55900911 Puliacation Year, Minneapolis, MN,USA,2010.

[13] Y. C. Choo, A. P. Agalgaonkar, K. M.Muttaqi, S. Perera and M. Negnevitsky, "Sub-synchronous Torsional InteractionBehaviour of Wind Turbine-Generator Unit Connected to an HVDC System,” University of Tasmania.

[14] Messina, A. Roman, S. C. A. Rivera, S. D. Olguin and V. D. Ruiz, "Development of Advanced Analytical Techniques for the Analysis of Sub-synchronous Torsional Interaction with FACTS Devices," Electric Power Engineering, 1999.

[15] M. Sahni, B. Badrzadeh, D. Muthumuni, Y. Cheng, H. Yin, Student Member, S-H. Huang, Member and Y. Zhou, "Sub-synchronous Interaction in Wind Power Plants- Part II: An ERCOT Case Study,” Power and Energy Society General Meeting, 2012 IEEE, pp. 1-9.

[16] B. Badrzadeh and S. Saylors, "Susceptibility of Wind Turbines to Sub-synchronous Control and Torsional Interaction," Transmission and Distribution Conference and Exposition (T\&D), 2012 IEEE PES, pp. 1-8. 